\title{
Comparison of successful abortion rate of mifepristone -Misoprostol combination with exrtaamniotic ethacridine lactate - misoprostol for termination of second trimester pregnancy
}

\author{
Hemavathi. $\mathbf{G}^{\mathbf{1}}$, Jagruthi $\mathrm{C}^{2, *}$ \\ ${ }^{1}$ Senior Resident, Dept. of Obstetrics and Gynecology, Koppal Institute of Medical Sciences, Koppal, Karnataka, \\ ${ }^{2}$ Junior Resident, Dept. of Obstetrics and Gynecology, Banglore Baptist Hospital, Hebbal Banglore, Karnataka, India
}

\section{*Corresponding Author: Jagruthi C}

Email: cjagruthi08@gmail.com

Received: $6^{\text {th }}$ August, 2018

Accepted: $11^{\text {th }}$ September, 2018

\begin{abstract}
Abortion procedure is one of the commonly practiced procedure in practice thereby demanding a safe and effective method of abortion.

Objective: Objective of study was to compare successful abortion rate and to compare the mean induction-abortion interval.

Materials and Methods: The present was undertaken among the patients admitted to hospitals attached to J.J.M. Medical College; Bapuji hospital, women and children hospital and Chigateri general hospital Davangere during the study period from November 2016 - October 2017. Patients are randomized in two groups. Patients coming for second trimester abortion to above mentioned hospitals were assigned serial number from one to eighty and all patients with even number will be allocated to group 1 and all patients with odd number will be allocated in group 2, each group comprising 40 women each.

Results: In the present study the mean induction abortion interval for group 1 was $19.56 \pm 1.82$ hours and group 2 was $14.13 \pm 2.72$ hours. This was statistically significant. Of the 40 cases in each group, 37 had complete abortion i.e. $92.5 \% 3$ cases (7.5\%) from both the groups had incomplete abortion and was supplemented with check curettage in both groups.

Conclusion: Ethacridine lactate instilled extra-amniotically then by vaginal misoprostol is safer and acceptable, has short I-A interval than mifepristone - misoprostol for $2^{\text {nd }}$ trimester termination of pregnancy.
\end{abstract}

Keywords: Abortion rate, Induction-abortion interval Extraamniotic; Ethacridine lactate, Mifepristone, Second trimester abortion, Misoprostol.

\section{Introduction}

Termination of pregnancy during mid trimester is among the most controversial areas of gynecological practice. $^{1,2}$ It has moral, emotional, social and technical issues. ${ }^{1,2}$ Many medical and surgical methods have been tried for $2^{\text {nd }}$ trimester MTP with varying success and induction abortion interval. ${ }^{3}$ Reasons for termination ar fetal demise, fetal anomalies, failure of contraception, determination of genetic and metabolic disorders, to safeguard maternal health. ${ }^{3-5}$

A combination of mifepristone, and misoprostol is effective for medical abortion in second trimester. Pretreatment with mifepristone adds to the efficacy of misoprostol as an abortifacient. ${ }^{3}$

The good regimen is still under investigation, but is required to be characterized by short induction abortion interval, low side effects, decreased surgical intervention, high abortion rate and high acceptability.

This study is therefore designed for comparison of successful abortion rate of mifepristone-misoprostol combination with exrtaamniotic ethacridine lactate misoprostol for termination of pregnancy $\left(2^{\text {nd }}\right.$ trimester). The objective of study was to compare successful abortion rate and to compare the mean induction-abortion interval.

\section{Materials and Methods}

The present was undertaken among the patients admitted to hospitals attached to J.J.M. Medical College; Bapuji hospital, women and children hospital and Chigateri general hospital Davangere. Patients admitted to the above mentioned hospitals during the study period of 1 year from November 2016 - October 2017 are included in the study. Permission for the study was obtained from the college authorities prior to commencement. Patients are randomized in two groups. Patients coming for second trimester abortion to above mentioned hospitals were assigned serial number from 1-80 and all patients with even number will be allocated to group 1 and all patients with odd number will be allocated in group 2, each group comprising 40 women each.

Inclusion Criteria: Healthy women aged between 21 to 35 years with singleton intrauterine pregnancy between 13 and 20 weeks of gestation admitted for termination of pregnancy.

Exclusion Criteria: Multiple pregnancies, grand multipara, cardiac, renal and liver disease, scarred uterus, ruptured membranes, placenta previa, hemoglobin less than $8 \mathrm{~g} \%$, hemorrhagic disorders \& treatment with anticoagulants, intolerance to misoprostol and ethacridine lactate.

Method: Gestational age is determined from first day of last menstrual period (LMP), Pelvic and bimanual 
examination. ${ }^{1,5}$ Urinary pregnancy test if done during early pregnancy. ${ }^{1}$

Obstetric ultrasonography is done when date of LMP is not known or where LMP and clinical findings differ. ${ }^{1,5}$

Informed written consent will be obtained from each patient. Selected patients will be registered, detailed history noted, routine investigations will be sent \& gestational age confirmed.

Group 1: A single dose of mifepristone 200mg orally given on admission, 12 hours later $400 \mu \mathrm{g}$ of misoprostol vaginally and $400 \mu \mathrm{g}$ repeated every 4 hourly if no response for maximum of 5 doses. Vaginal examination done every 4 hours.

Group 2: $0.1 \%$ extraamniotic ethacridine lactate $(10 \mathrm{ml}$ per week of gestation to maximum of $150 \mathrm{ml}$ instilled using Foleys catheter, bulb inflated with $20 \mathrm{ml}$ of distal water) followed 6 hourly by intravaginal misoprostol $400 \mu \mathrm{g} / 4$ hourly if no responses for maximum of 5 doses. Four hourly vaginal examination done.

Foley's catheter removed after 24 hours if not expelled out spontaneously.

Patient in each group will be explained regarding the dosage schedule, side effects like nausea/vomiting, diarrhea, headache, fever, chills, abdominal cramps and complications such as hyperstimulation, cervicovaginal tear, uterine rupture.

Pulse rate, blood pressure, uterine contraction will be noted every 4 hours.

The induction-abortion interval is calculated as time taken from initial insertion of mifepristone / ethacridine lactate to time when fetus \& placenta aborted. ${ }^{4}$

Complete abortion is defined as the expulsion of fetus and placenta without operative interventions. ${ }^{5}$

If placenta appears complete, no further interventions will be undertaken.

If placenta is incomplete or fails to get expelled, suction evacuation or check curettage will be done. ${ }^{4}$

Those who did not expel fetus by 48 hours are considered failures. ${ }^{1,5}$

\section{Data Analysis}

SPSS (version 16) was used for all the analysis. Mean \pm SD, and range values for continuous data and Number and percentages for categorical data. T-test (unpaired) was used to compare the mean values. Chisquare test was used to analyse the catagorical data. A $\mathrm{P}$-value of 0.05 or less was considered for statistical significance.

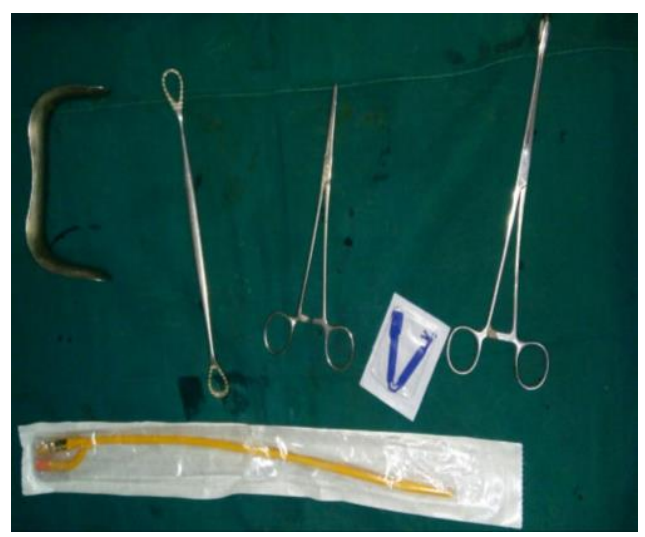

Fig. 1: Instruments used for ethacridine lactate instillation

\section{Results}

Majority of the cases in both the groups were between 21-25yrs the mean age was 24.7 $\pm 4.0 y$ rs in group 1 and $25.8 \pm 4.4 y r s$ in group 2. Range in both the groups was 21-35yrs. ( $\mathrm{P}$ value $>0.05$ ). Most of the participants in the groups were multigravidas. In group1, $42.5 \%$ were primigravida and $57.5 \%$ were multigravida. In group 2, 30.0\% were primigravida and $70.0 \%$ were multigravida. Eleven cases from group 1 and 12 cases from group 2 were of gestational age between 14-16 wks. 29 pregnant women from group 1 and 28 cases from group 2 were of gestational age between 18-20 wks

Mostly of the cases were aborted in both the group for anomalous fetus as indication, followed by IUFD, MTP+Tubectomy and humanitarian grounds.

Table 1: Indications for abortion

\begin{tabular}{|l|c|c|c|c|}
\hline \multicolumn{1}{|c|}{ Indications } & & Gr 1 & Gr 2 & Total \\
\hline \multirow{2}{*}{ Anomalies } & No. & 15 & 23 & 38 \\
\cline { 2 - 5 } & $\%$ & $37.5 \%$ & $57.5 \%$ & $47.5 \%$ \\
\hline \multirow{2}{*}{ IUFD } & No. & 11 & 10 & 21 \\
\cline { 2 - 5 } & $\%$ & $27.5 \%$ & $25.0 \%$ & $26.3 \%$ \\
\hline \multirow{2}{*}{ MTP+Tubectomy } & No. & 8 & 6 & 14 \\
\cline { 2 - 5 } & $\%$ & $20.0 \%$ & $15.0 \%$ & $17.5 \%$ \\
\hline \multirow{2}{*}{ Humanitarian } & No. & 6 & 1 & 7 \\
\cline { 2 - 5 } & $\%$ & $15.0 \%$ & $2.5 \%$ & $8.8 \%$ \\
\hline \multirow{2}{*}{ otal } & No. & 40 & 40 & 80 \\
\cline { 2 - 5 } & $\%$ & $100 \%$ & $100 \%$ & $100 \%$ \\
\hline Chi-Square & 5.59 & $\mathrm{P}=0.13, \mathrm{NS}$ & & \\
\hline P > 0.05, Not Sig. & & & & \\
\hline
\end{tabular}


Sixty five percent of the cases in group 1 used 1-2 doses of misoprostol whereas mean dose of misoprostol used was 2.3. 82.5\% of the pregnant women in group 2 used 1-2 doses of misoprostol whereas misoprostol dose was 1.9 .
The amount of misoprostol used in group $1(2.3 \pm 0.6$ doses co-related with $920 \pm 240 \mu \mathrm{g}$ of misoprostol) and group $2(1.9 \pm 0.6$ doses co-related with $760 \pm 240 \mu \mathrm{g}$ of misoprostol) was significant. $\mathrm{p}<0.001$

Table 2: Number of dose of misoprostol used

\begin{tabular}{|l|c|c|c|c|}
\hline No. of Misoprostol & & Gr 1 & Gr 2 & Total \\
\hline \multirow{2}{*}{$1-2$} & No. & 26 & 33 & 59 \\
\cline { 2 - 5 } & $\%$ & $65.0 \%$ & $82.5 \%$ & $73.8 \%$ \\
\hline \multirow{2}{*}{$3-4$} & No. & 14 & 7 & 21 \\
\cline { 2 - 5 } & $\%$ & $35.0 \%$ & $17.5 \%$ & $26.3 \%$ \\
\hline \multirow{2}{*}{ Total } & No. & 40 & 40 & 80 \\
\cline { 2 - 4 } & $\%$ & $100 \%$ & $100 \%$ & $100 \%$ \\
\hline Mean \pm SD & $2.3 \pm 0.6$ & $1.9 \pm 0.6$ & - \\
\hline Gr 1 v/s Gr 2 & \multicolumn{3}{|l|}{$\mathrm{t}=10.50, \mathrm{p}<0.001, \mathrm{HS}$} & \\
\hline \multicolumn{2}{|l|}{ Unpaired t test } & \multicolumn{4}{|l}{} \\
\hline
\end{tabular}

In the present study the mean induction abortion interval for group 1 was $19.56 \pm 1.82$ hours and group 2 was $14.13 \pm 2.72$ hours.

Table 3: Induction to abortion interval

\begin{tabular}{|c|c|c|c|c|}
\hline $\begin{array}{l}\text { Induction- Abortion } \\
\text { Interval (Hrs) }\end{array}$ & & Gr 1 & Gr 2 & Total \\
\hline \multirow[t]{2}{*}{$<12 \mathrm{Hrs}$} & No. & 0 & 7 & 7 \\
\hline & $\%$ & $0.0 \%$ & $17.5 \%$ & $8.8 \%$ \\
\hline \multirow[t]{2}{*}{$12--18 \mathrm{Hrs}$} & No. & 5 & 28 & 33 \\
\hline & $\%$ & $12.5 \%$ & $70.0 \%$ & $41.3 \%$ \\
\hline \multirow[t]{2}{*}{$18--24 \mathrm{Hrs}$} & No. & 35 & 5 & 40 \\
\hline & $\%$ & $87.5 \%$ & $12.5 \%$ & $50.0 \%$ \\
\hline \multirow[t]{2}{*}{ Total } & No. & 40 & 40 & 80 \\
\hline & $\%$ & $100 \%$ & $100 \%$ & $100 \%$ \\
\hline \multicolumn{2}{|c|}{ Mean Age \pm SD (Hrs) } & $19.56 \pm 1.82$ & $14.13 \pm 2.72$ & \multirow[t]{3}{*}{ - } \\
\hline \multicolumn{2}{|l|}{ Range } & $16-23 . \mathrm{Hrs}$ & $9-21.5 \mathrm{Hrs}$ & \\
\hline \multicolumn{2}{|c|}{ Gr 1 v/s Gr 2} & \multicolumn{2}{|c|}{$\mathrm{t}=10.50, \mathrm{p}<0.001, \mathrm{HS}$} & \\
\hline Unpaired $t$ test & & & & \\
\hline
\end{tabular}

Of the 40 cases in each group, 37 had complete abortion i.e., $92.5 \% 3$ cases $(7.5 \%)$ from both the groups had incomplete abortion and was supplemented with check curettage in both groups.

Table 4: Outcome in two groups

\begin{tabular}{|l|c|c|c|c|}
\hline Outcome & & Gr 1 & Gr 2 & Total \\
\hline \multirow{2}{*}{ Complete } & No. & 37 & 37 & 74 \\
\cline { 2 - 5 } & $\%$ & $92.5 \%$ & $92.5 \%$ & $92.5 \%$ \\
\hline \multirow{2}{*}{ Incomplete } & No. & 3 & 3 & 6 \\
\cline { 2 - 5 } & $\%$ & $7.5 \%$ & $7.5 \%$ & $7.5 \%$ \\
\hline \multirow{2}{*}{ Total } & No. & 40 & 40 & 80 \\
\cline { 2 - 5 } & $\%$ & $100 \%$ & $100 \%$ & $100 \%$ \\
\hline
\end{tabular}

\section{Discussion}

The induction abortion interval obtained in group 2 is comparable with other studies done by different authors on extraamniotic ethacridine lactatemisoprostol for IInd trimester termination and found to be shorter than other studies. 


\begin{tabular}{|c|c|}
\hline Authors & Extraamniotic ethacridine-vaginal misoprostol \\
\hline Mamta $\mathrm{G}$ et al ${ }^{6}$ & $18.3 \pm 6.1$ hours \\
\hline Siddareddy $\mathrm{Y}$ et al ${ }^{47}$ & 16.44 hours \\
\hline Jyothi IS et al $^{2}$ & $19.8 \pm 10.15$ hours \\
\hline Present study & $14.13 \pm 2.72$ hours. \\
\hline
\end{tabular}

In the year 2011, Tripti and Namrata in their study concluded that pretreatment with mifepristone 12 hours prior to intravaginal misoprostol improves the induction abortion interval $\left(6.72 \pm 2.26\right.$ hours). ${ }^{3}$ I-A interval is taken from administration of misoprostol. From administration of mifepristone to abortion, time is $18.72 \pm 2.26$ hours. In present study, above interval was $19.56 \pm 1.82$ hours which are comparable.

Neelamma Patil, Priyanka Gupta, Megha D. Hittinhalli, Subhaschandra R. Mudanur, Manpreet Kaur J. et al conducted a study in 2017 to compare the efficacy of preinduction with mifepristone 12 hours versus 24 hours prior for second trimester pregnancy termination and found induction abortion interval was 9.3 hours when misoprostol given 12 hours after mifepristone. ${ }^{47}$ Induction abortion interval is taken from administration of misoprostol. Time from administration of mifepristone to abortion is 21.3 hours. In our study, the induction abortion interval is taken from the time of administration of mifepristone to abortion which was $19.56 \pm 1.82$ hours. Hence the results are comparable.

Same study conducted by Smiti Nanda and Anshu Pau et al showed the induction-to-abortion interval in the mifepristone- misoprostol group, $58.31 \pm 3.62$ hours with complete abortion rate of $90 \%$. In the study misoprostol was given 48 hours after administering mifepristone. Mean time from misoprostol to abortion was $10.54 \pm 5.81$ hours. ${ }^{4}$ In our study, misoprostol is given 12 hours from mifepristone and the induction abortion interval is taken from the time of administration of mifepristone to abortion which was $19.56 \pm 1.82$ hours with complete abortion rate of $92.5 \%$. Hence the results are comparable.

RCOG Best practice recommends that fourteen weeks and more period of gestation should undergo medical termination in a medical facility. Mifepristone and misoprostol should be used to shortens the induction interval. ACOG recommends mifepristone $200 \mathrm{mg}$ orally followed in $24-48$ hours by misoprostol $800 \mu$ gm vaginally followed by $400 \mu$ gm every 3 hours maximum of 5 doses. If abortion is not complete after 5 doses, the women may rest before starting next cycle. ${ }^{47}$

The recommended method for medical abortion by WHO is $200 \mathrm{mg}$ mifepristone administered orally followed 36 to 48 hours later by repeated doses of misoprostol. The initial misoprostol dose following oral mifepristone administration may be either $800 \mu \mathrm{gm}$ administered vaginally or $400 \mu \mathrm{gm}$ administered orally. Subsequent misoprostol doses should be $400 \mu \mathrm{gm}$, administered either vaginally or sublingually, every 3 hours up to four further doses ${ }^{47}$

The suggested protocol by FOGSI is also mifepristone $200 \mathrm{mg}$ followed by misoprostol $400 \mu \mathrm{gm}$ after 36-48 hours either oral, sublingual or vaginal every 4-6 hours for maximum of 5 doses. ${ }^{47}$ But present study proved that the duration between mifepristone and misoprostol can be reduced to 12 hours without affecting the efficacy.

Comparison of complete abortion rate of present study with different studies shown below:

\begin{tabular}{|c|c|c|}
\hline Authors & Mifepristone -misoprostol & Ethacridine -misoprostol \\
\hline Nanda $\mathrm{S}$ et al, ${ }^{4}$ & $90 \%$ & - \\
\hline Mamta G et al ${ }^{6}$ & - & $83.33 \%$ \\
\hline Jyothi IS et al ${ }^{2}$ & - & $72 \%$ \\
\hline Nagaria $T$ et $\mathrm{al}^{3}$ & $95 \%$ & - \\
\hline Patil $\mathrm{N}$ et $\mathrm{al}^{47}$ & $100 \%$ & - \\
\hline Siddareddy $\mathrm{Y}$ et al ${ }^{46}$ & - & $99 \%$ \\
\hline Present study & $92.5 \%$ & $92.5 \%$ \\
\hline
\end{tabular}

If placenta is incomplete or fails to get expelled, suction evacuation or check curettage will be done. ${ }^{4}$

3 cases $(7.5 \%)$ from both the groups had incomplete abortion and was supplemented with check curettage in both groups

\section{Conclusion}

Misoprostol had synergistic effect with prostaglandin released due to stripping of membranes from extra-amniotic Ethacridine. With this combination success rate was high $(92.5 \%)$, with short induction abortion interval, less rate of incomplete abortion without any major complications. Thus, ethacridine lactate instilled extra-amniotically followed by vaginal misoprostol is effective, safer and acceptable, has short induction abortion interval than mifepristone misoprostol. 


\section{References}

1. Biswas SC, Dey R, Jana R, Chattopadhya N. Comparative study of intravaginal misoprostol and extraamniotic ethacridine lactate instillation for mid trimester pregnancy termination. J Obstet Gynecol India. 2007;57(3):210-12.

2. Jyothi IS, Reddy KA, Saritha A. Comparative Study of Efficacy of Extra-amniotic Ethacridine Lactate with Oxytocin versus Extra-amniotic Ethacridine Lactate with Intravaginal Misoprostol for Termination of Pregnancy with IUD Anamolous Fetuses in Second and Third Trimesters. Indian Journal of Mednodent and Allied Sciences. 2015;3(3):155-60.

3. Nagaria T, Sirmor N. Misoprostol versus mifepristone and misoprostol in second trimester termination of pregnancy. The Journal of Obstetrics and Gynecology of India. 2011;61(6):659-62.

4. Nanda S, Paul A. Comparison of efficacy and safety of mifepristone-misoprostol combination with ethacridine lactate in mid-trimester termination of pregnancy. International Journal of Medicine and Medical Sciences. 2013;5(6):307-11.

5. Chaudhuri S, Mitra SN, Chaudhuri N, Chattopadhya D, Banerjee D, Bose S. A comparison of intravaginal misoprostol with extraamniotic etharidine lactate for second trimester MTP. J Obstet and Gynecol India. 2006;56(6):518-21.

6. Mamta G, Kant SK, Ramavatar B, Gupta S. Comparative Study of Intravaginal Misoprostol Alone 'Versus' Extra Amniotic Ethacridine Lactate Instillation Followed by Intravaginal Misoprostol' for Mid Trimester (13-20 Weeks) Termination of Pregnancy. IOSR Journal of Dental and Medical Sciences (IOSR-JDMS). 1(15):129-32.

7. Yashvardhini Siddareddy, Himabindu Sangabathula. A comparative study of ethacridine lactate with vaginal misoprostol versus vaginal misoprostol alone for mid trimester abortion. IAIM, 2017;4(6):38-44

8. Patil N, Gupta P, Hittinhalli MD, Mudanur SR, Tehalia MKJ, Nemagouda AS et al. A randomised controlled trial to compare the efficacy of preinduction with mifepristone 12 hours versus 24 hours prior for second trimister pregnancy termination. Int J Reprod Contracept Obstet Gynecol. 2017;6:3628-32.

How to cite this article: Hemavathi. G, Jagruthi C. Comparison of successful abortion rate of mifepristone-Misoprostol combination with exrtaamniotic ethacridine lactate - misoprostol for termination of second trimester pregnancy. Indian J Obstet Gynecol Res. 2018;5(4):471-475. 